\title{
Perceptions of participants' incentives and attitude of Second Chance School learners
}

\author{
Vasiliki lliopoulou
}

Secondary education teacher Ministry of Education Greece

Email:vaseliop@hotmail.com

Accepted 15 $5^{\text {th }}$ August, 2019.

\begin{abstract}
The purpose of this study is to present adults' (over 18 years who have not completed the nine-year compulsory education for various reasons) motivation for participation in Second Chance Schools (SCSs) curriculum as well as to highlight these learners' perceptions of their involvement in this educational program. Besides, it will refer to SCS learners' attitudes and perspectives about these schools, their function and their offer to their students.
\end{abstract}

Keywords: Second Chance Schools, perceptions, attitudes

\section{Second Chance Schools as an institution.}

Second Chance Schools (SCSs) are an innovative institution established in many member states in Europe, as well as in Greece, as a way of combating social exclusion. This institution is targeted at citizens of eighteen (18) years or older who have not completed nine year compulsory education, thus endangering social exclusion and marginalization. This institution enables these individuals to obtain a high school leaving certificate and to integrate smoothly into the social, economic and professional structures. The current SCS regulation (Government Gazette 1003/22-07-2003) defines the purpose and the individual objectives of SCSs, describing their basic principles and characteristics, their curriculum and their organization. In addition, it refers to issues such as: staff selection and teacher apprenticeships, the administrative bodies of SCSs, their cooperation with local authorities, and the registration, attendance and evaluation of students (trainees).

A Second chance school (SCS) training program is flexible, since it is tailored to the educational needs of learners, to the needs of modern society and to the workplace. It is based on the principle of multilingualism, so that the trainee-learner can acquire all those skills coming from different fields and will help him/her organize his / her personal, professional and social life. The main core of the program consists of linguistic, numerical and computer literacy. Language literacy refers to Greek and English, arithmetic is based on the subject of mathematics, and computer literacy is supported by computer science and is carried out in a computer lab. Additionally, the program includes science literacy related to natural sciences, social literacy based on socio-cultural anthropology, environmental literacy based on environmental education and literacy in aesthetic and cultural education.

The SCS curriculum requires the use of modern teaching methods that are applied to the principles of Adult Education and Lifelong Learning (Hondolidou, 2003: 76), such as group co-operation and project method, as well as workplace learning (European Commission, 2000). In general, participatory teaching methods, which favor the interaction between teacher and students (trainees) as well as the beneficial methods in which learners themselves or in groups discover the knowledge, are preferred. Some basic teaching techniques used are discussion, role play, brainstorming, work groups, educational visits and the project. The total duration of the curriculum is eighteen (18) months and is divided into two nine month terms with a weekly twenty 
(20) hour school timetable (Hondolidou, 2003: 75-80).

The link between school, local society and the labor market is achieved through the institution of career guidance provided by SCSs. The career counselor has both individual and group counseling to meet the needs of trainees-students. The activities that take place are related to self-knowledge, self-esteem, professional decision-making and life skills. In addition, it is responsible for providing educators with educational and professional information. In addition to the career counselor, each SCS also has a psychologist adviser who takes care of the psychological support of learners in their social reintegration efforts, as well as of the teachers who have to deal with a particular group of students.

The main objective of the program is to "improve the access to knowledge of people at risk of social exclusion by engaging experienced teachers, adapting teaching methods to the needs of learners, creating new incentives, using multimedia and promoting sections with fewer pupils" (European Commission, 2000).

In this context, the European Commission (2005) set out key principles that should characterize the operation of Second Chance Schools. Specifically:

- $\quad$ Tied cooperation between local authorities, social services and organizations and the private sector, with the latter being a key source of training and future jobs.

- Alternative teaching and counseling approach that focuses on individual needs, interests and competences and motivates active learner learning.

- Flexible school units that enable basic skills (literacy, numeracy, social skills) combined with practical business training.

- A central role in acquiring skills in information technology and new technologies.

- School working in areas where young people live or gather.

In this way, an overall strategy for the regeneration of urban areas is being promoted, while opening up new horizons both for young people and for the urban environment in which they live and work. According to the Law 3369/2005 on the "Systematisation of Lifelong Learning", SCSs are part of the new Lifelong Learning Grid and it is made clear that they are addressed to "people who have not completed Compulsory Education" (Article 2) and that the approval of their programs are made by decision of the Secretary General of Adult Education, following the opinion of the National Lifelong Learning Committee (article 6, par. 1), regarding the programs funded by the General Secretariat for Adult Education. The title awarded by a SCS is equivalent to the lower secondary education school -Gymnasium Certificate and it is recognized by ASEP.

Finally, under this title, SCS graduates are able to continue their studies: at the higher secondary education school - Lyceum (General, Vocational, Evening) in post- secondary IEK, post-secondary departments of OAED at Adult Education Centers, Parents' Schools and in autonomous programs of GSGE for secondary school graduates at the Center for Lifelong Learning and Distance Learning of GGEE. The funding of Second Chance Schools has been done so far with both National and Community Resources (European Commission, 2005).

\section{Incentives and action.}

The motivations are instincts, urges, various goals, desires, or various intentions and feelings (internal causes), as well as rewards, lures or fears or repulsive irritations (external causes) (Kostaridou-Euclidi, 1999: 17) and related to the preparation of action, the formation of desire and its assessment of how desirable something is and what chances it has to be fulfilled (Boekaerts 2002: 5). The expectation of a positive result in the fulfillment of desire implies an intention for action (Kostaridou-Euclidi, 1999: 21, Bakirtzis 2000: 95-96, Boekaerts 2002: 5). This intention, given the appropriate external circumstances, shapes the action in order to achieve the goal. Of course, any behavior is not necessarily the product of motivation, intent, and willful processes. Reflective reactions and our daily, automated actions, what we call habits, are excited and executed without going on a conscious level without conscious intention and willful control.

Thus, motives may be inherent or acquired, that is, whether they are inherited (eg instincts) or formed within the environment where a person lives and grows. They are also distinguished in normal motives and serve the individual's life and in psychological motives and relate to personality (Kostaridou-Euclidi, 1999: 17). Incentive psychology mainly explores which and how many incentives exist. In the present work, however, we will refer to those motives related to the individual's level of ambition, namely the motivation to achieve (KostaridouEuclidi, 1999: 131-148), because it is directly related to the subject of study.

\section{Achievement Incentive.}

First, before analyzing this incentive, it is advisable to refer to the level of ambition. Ambition refers to a decision that the individual wants to take for his/her future by doing so in a similar way in the past. When performing this act, the person knows his/her performance in this work he/she is called to repeat. The motivation to achieve, in turn, is that push to the individual to act in order to achieve a result, better than he/she had achieved in previous actions. So it tries to satisfy the person's "ambitions". In addition, the motivation to achieve is stimulated when the decision that the person is asked to take is also surrounded by a reward for his/her performance. The above are accompanied by emotions, 
both positive and negative. The positive ones create an expectation for the outcome of the actions, while the negative ones are related to the risk of failure (Kostaridou-Euclidi, 1999: 130-131). In this case, as we shall see below, as a motivation to achieve, it can be considered the acquisition of the lower secondary school diploma, which will help to improve his/her job or to find work or to improve his/her educational level.

\section{Involvement of learners in SCSs.}

Adult education programs are generally not mandatory. The participation of students (trainees) is voluntary and optional, except for some exceptions where the students' working environment requires it. This voluntary follow-up of educational programs is motivated by various motivations, which involve "negative and positive feelings, linked to the individual's goal" (KostaridouEuclidi, 1999: 132). Accordingly, with the theory of motivation for achievement and ambition developed in previous paragraphs $(2.1,2.1 .1$ and 2.1.2), in our case, the motivation of learners may be due to internal or external factors. Internal factors are considered instincts, urges, goals, desires or intentions, emotions, emotional states, and so on while external factors are rewards, lures or fears, repellent mechanisms, etc.

People who choose to attend SCSs are being pushed into this decision to meet some of their needs. Thus, a number of incentives have been observed, which occur in each of them individually or at the same time. It appears that the majority of a SCS program evaluation for the school years 2001-2002, 2002-2003 (Vergidis, 2003) refers to vocational rehabilitation and the improvement of the existing job. Perhaps for this reason, as the most positive element of SCSs study, the lessons and knowledge they offer are considered, according to a survey carried out on the characteristics and cultural capital of the SCSs in Patras, Pyrgos and Agrinio (Landritsi, 2007), obviously giving great importance to the acquisition of educational goods in order to compensate for their educational shortcomings and to strengthen their educational capital.

In the same survey, it appears that these individuals, through the second chance they are given, want to get the equipment they lacked at their first "opportunity." They expect the lower secondary school certificate to offer them a "legitimate opportunity for social advancement and to provide the springboard for diversified access possibilities" (Landritsi, 2007: 112). In addition to the knowledge that will be the means for their professional rehabilitation or improvement, SCS learners expect at the same time to study and develop other skills. In particular, with the development of their social skills, they are expected to acquire a more "positive and energetic attitude as creative members of modern society at personal, family, social and professional level". Landritsi, 2007: 112). Apart from the education that they will acquire, they expect to evolve positively, upwardly, themselves and their way of life, envision the experience of feelings to feel more "useful" to their children by offering them their knowledge and eventually hoping to improve their interpersonal relationships (Landritsi, 2007: 112).

The motivation, which concerns the personal and family environment (improvement of the self-image, offering of cultural goods to the family), is more pronounced referring the students- learners of the first school year (cycle), through empirical research (in Pyrgos, Patras, Agrinio) (Landritsi, 2007: 29) compared to second year (cycle) students- learners. The expectation of selfimprovement, confidence-building and lifestyle improvement show that school continues to contribute to social inclusion and is not only a means of transition and indeed a greater chance of success - in working life. Finally, there are few students- learners wishing to continue their education at higher education and training levels in order to further improve their job position. In particular, a high percentage of students aims at attending TEEs (Landritsi, 2007: 92), combined with the acquisition of a high school diploma, as well as expectation of attendance at IEK, OAED even in Universities. (Landritsi, 2007: 74).

\section{Learners' perceptions of SCSs.}

Since the moment SCSs started working, a number of surveys have been carried out related to learners' perceptions of the SCS they are attending. Partly, this image of the learners for their school can also come from their answers on the evaluation sheets that complement, evaluating both the school unit and the teachers-trainers, therefore the quality of the education provided. Thus, both positives and negative issues concerning SCSs in which they are studying arise, finds of considerable interest. In many places it is logical to have contradictory perceptions, since it is not possible for all students (trainees) to perceive and evaluate the data in the same way. The experience and the personality of the person, which are the means for shaping and (re)identifying his / her perceptions, always play an important role.

\section{Positive perceptions of SCS learners.}

In previous empirical researches, which have been made about the perceptions of students (trainees) in various SCSs, the students (especially the first school year students and secondly the second school year students) regard the philosophy and the way of functioning of the SCS they attend (Alexopoulou, 2006: 75, Anadiadis, 2007: 38, Landritsi, 2007: 111). Also, even a few students-trainees mention the SCS duration of study (Landritsi, 2007: 85), the timetable (Lazou, 2008: 56), the lack of evaluation (Landritsi, 2007: 91-92) the 
complementary (advisory) services these schools offer (Alexopoulou, 2006: 96), but also workshops and action plans (Ananiadis, 2007: 38) as positive aspects and features of SCSs. In addition, only positive opinions are expressed about the pedagogical climate, the contribution of teachers and the way of teaching, (Landritsi, 2007: 86). Characteristically, they refer to teachers' understanding and friendly attitude towards their problems (Lazou, 2008: 39). The only observations that appear to be expressed relate to the absences of certain specialties. Students (trainees) (Lazou, 2008: 58), distinguish the need for permanent and properly trained staff.

Positive perceptions about SCSs are also shaped by students, with a view to their return to the school environment, the development of communication and, of course, the development of self-confidence (Landritsi, 2007: 87). In particular, in order to develop their selfconfidence, SCS students report that in the course of their studies in a SCS they constantly observe changes in the way of thinking, functioning and addressing everyday problems (Ananiadis, 2007).

What matters is that students (trainees) have crystallized their preferred learning style and usually revolve around free dialogue and open communication, unlike the monologue of their teacher (trainer), which repels them (Kokkos, 2005: 88-89). Thus, they state that they learn what each person really needs, in a climate of free expression and acceptance, in pleasant ways (Alexopoulou, 2006: 96).

\section{Negative and contradictory perceptions of learners about SCSs.}

Negative data from empirical research about SCSs, according to students (trainees), revolve around building facilities and their spatial distribution. A percentage of students, considered SCS organization, the school timetable, lack of evaluation, the duration of study and supplementary services to be negatives features of these schools. Few students (trainees) refer to infrastructure facilities and educational material. Only a few students of these ones are unhappy and mainly with the infrastructure facilities (Vergidis, 2003: 126-127, Landritsi, 2007: 86). Most of the students are generally satisfied with the material they take in photocopies because they do not have time to read books at home (Lazou, 2008: 56), although there are always students who prefer school books to photocopies.

Some SCS students think that the heterogeneity among learners (in terms of the educational level in particular), the cost of their going to school and back home and the behavior of their "fellow students" are considered to be negative elements of SCSs " (Vergidis, 2003: 126-127, Landritsi, 2007: 90).

Regarding literacy (courses), they usually find it interesting (Ananiadis, 2007: 38, Lazou, 2008: 56), although there are conflicts, since some students consider that their level is low. This is due to the fact that in SCSs there are usually two types of trainees: those who have the ability and the level to move faster and are interested in continuing their studies at TEE. or at higher secondary school and those who would like to be helped in the lessons to get only the lower secondary school diploma (Vergidis, 2003: 126-127, Landritsi, 2007: 112). Thus, it is likely that those students who want to continue in high school will have more requirements than the curriculum, perhaps even wanting the convergence of the SCS courses with "typical" education.

According to the results of these empirical surveys, the views of learners on some issues are contradictory. For example, the lack of evaluation is considered positive by some students while by some others negative. Similarly, contradictory results are also observed about the duration of the study and the teaching hours, as well as the teaching material. Controversial views also arise for action plans, since some are also considered to be positive while other students think they are negative.

By observing and carefully examining the perceptions (positive and negative ones) of students, it can be concluded that in general their opinion about SCSs is positive, since the majority of them believe that there are no negative elements in their studies.

\section{Students' attitudes towards SCSs.}

As it is shown in the Anadiadis empirical survey (Ananiadis, 2007). Second Chance School Students' Perceptions of the image of themselves (self-esteem)), some students starting their SCS course face their new life situation having positive mood and enthusiasm and being willing to participate in anything and to work with teachers in various activities. Another group of students, on the contrary, not knowing anything about the new school environment and the SCS philosophy and having in mind the traditional typical school they left years ago, come to school and attend lessons scared and skeptical about what they will meet as members of a class throughout the educational process.

In general, however, students (trainees) are in tune with the operation of the new school and the new teaching methods and are gradually participating in the whole educational process. Then, they are enthusiastic about the lectures - lectures, which are done through group teaching and teacher coordination, as well as workshops and action plans (Ananiadis, 2007: 37).

The experiences of SCS learners seem to be different from what they used to have in the past, that is to say, as students of typical education, while their positive opinion of SCS results mainly from the innovative way in which the educational process takes place as a whole. Also, the image they had about the mode of operation was far from 
what SCSs were. Of course, it is logical for all students to carry with them the (positive or negative) experiences of the "typical" school and the SCS, which in turn influences their behavior as adult learners (Landritsi, 2007: 91-92, Lazou, 2008: 41).

For many of them, their school image is accompanied by images of oppression, workload, rigid programs and feelings of disability and failure (Landritsi, 2007: 111, Lazou 2008: 41). They associate performance with rating, controlling their course through written tests, and even acquiring knowledge with the necessity of having a school book (Landritsi, 2007: 110). These elements of previous experiences often result in the reproduction of similar emotions and attitudes, which in the beginning are a serious obstacle to their participation in the program (Lazou, 2008: 41).

Thus, often a number of students adopt and manifest a behavior similar to that of their typical school years, i.e. a passive attitude that wants teachers to teach because they are the ones who know everything (Landritsi, 2007: 110), while at the same time they want their active participation, as mentioned in the characteristics of adult learners is their "active participation in issues that concern them" (Kavadias et al., 2007: 59). The result of these contradictions is that some students comply with the data while others seek, to some extent, independent learning (Rogers, 1999: 105).

It is clear from the above, that individuals who choose to study at SCSs are encouraged to make this decision in order to meet their needs fulfill their targets. Thus, a number of motives have been observed, which occur in each of them individually or simultaneously. Most of these incentives refer to vocational rehabilitation and improvement of the existing job. Perhaps for this reason, the most positive element of studying at SCSs is the courses and the knowledge they offer, obviously giving too much importance to the acquisition of educational goods, so as to offset their educational deficiencies and to enhance their educational capital.

It also appears that these individuals, through the second opportunity given to them, wish to obtain the supplies deprived of their first 'opportunity'. But apart from the knowledge they will provide for their vocational rehabilitation or improvement, SCS learners (trainees) expect at the same time their education and development of other skills, social skills as well as a positive attitude as members of society on a personal, family, social and professional level. They feel useful and able to offer and improve both themselves and their family standard of living. The motivations, related to personal and family space (improving self-image, offering cultural goods to the family), are also very often and intense. Expectations of self-improvement, self-esteem, and lifestyle improvement show that school continues to contribute to social inclusion.

Finally, one can conclude that in general the picture SCS learners have about their school is positive, as most of them consider that there are no negative elements in their studies and studying at a SCS can give them more advantages than disadvantages at almost every field of their personal, social or professional life.

\section{REFERENCES}

Alexopoulou E (2006). Investigating students' perceptions at Secondary School Opportunity Tower, on the effectiveness of Career Counseling for their smooth integration into the labor market. Bachelor's thesis. Greek Open University - School of Humanities, Studies in Education.

Ananiadis P (2007). Second Chance School Students' Perceptions of the image of themselves (self-esteem). Bachelor's thesis. Greek Open University-School of Humanities, Studies in Education.

Bakirtzis K (2000). Experience and motivation for learning. Pedagogical inspection, Organization \& Operation of Second Chance Schools 2004. Available at website: http://www.ideke.edu.gr/uploads/news_355.pdf.

Boekaerts M (2002). Motivation to learn. (Mctáppaon: Maupookoúpns $\triangle$.K.), International Academy of Education International Bureau of Education- IBE UNESCO, EDUCATIONAL PRACTICIES SERIESNo 10.

European Commission (2000). "Second Chance Schools" Summary Report on the evaluation of the European Pilot Schools. Berlin.

European Commission (2005). Eurybase. The Information Database on Education Systems in Europe. Greece. 41.

Government Gazette 1003/22-07-2003. "Organization and Operation of Second Chance Schools".

Hondolidou E (2003). The Second Chance Schools Curriculum. Curriculum Specifications for Second Chance Schools, IDEKE.

Kavadias K, Kioulanis SP, Metis S, Orlis ST (2007). In-school training as a key factor in the effectiveness of the educational process in SCSs: an alternative proposal for in-service teacher training. Proceedings of Second Phase Secondary School Reporting Conference Athens 23-24 June 2006, Ministry of Education.

Kokkos A (2005). Adult education. Detecting the field. Athens: Metechmio.

Kostaridou-Euclidi A (1999). Incentive Psychology. Athens: Greek Letters, at version.

Landritsi I (2007). Second Chance School Students: A Survey on characteristics and their cultural capital in the SBS of Patras, Pyrgos and Agrinio, University of Patras- School of Social and Humanities Education Department of Primary Education - Postgraduate Program of Studies.

Lazou A (2008). Learners' views on the barriers to learning that face in Second Chance Schools. The case of SBS Pyrgos. Thesis Work. Hellenic Open University - School of Humanities, Studies in Education.

Rogers A (1999). Adult education, (ed. M. Papadopoulou \& M. Tombrou). Athens: Metechmio.

Rogers A (2001). Adult learners: Characteristics, Needs, Learning modes, at A. Kokkos (ed.), International Conference on Adult Education. Athens: Metechmio.

Vergidis D (2003). Evaluation of the SBS program for the 2001/02 school years 2002/03. University of Patras - School of Humanities and Social Sciences, Continuing Education and Training Laboratory. 